\title{
The development of the BK-SE36 malaria vaccine candidate
}

\author{
Nirianne MQ Palacpac ${ }^{*}$, Masanori Yagi ${ }^{1}$, Edward Ntege ${ }^{2}$, Betty Balikagala $^{2}$, Adoke Yeka ${ }^{2,3}$, Hiroki Shirai ${ }^{4}$, \\ Nahoko Suzuki ${ }^{4}$, Takuya Okada ${ }^{4}$, Bernard Kanoi ${ }^{2}$, Arisue Nobuko', Takahiro Tougan', Ken J Ishii ${ }^{5}$, \\ Thomas G Egwang ${ }^{2}$, Toshihiro Horii ${ }^{1}$
}

From Challanges in malaria research: Core science and innovation

Oxford, UK. 22-24 September 2014

Complex and widespread with about $90 \%$ of the global burden in sub-Saharan Africa, malaria remains a significant health problem. Malaria vaccines have the chance to make significant inroads, with RTS,S vaccine candidate as the most advanced candidate. However, the need for a highly efficacious, long-lasting vaccine is still unmet. Continued support for a repertoire of tools for Plasmodium falciparum is needed. A blood-stage vaccine is desirable to deal with morbidity and mortality secondary to P. falciparum infection, and thus would be a valuable strategy in the fight against malaria.

The $P$. falciparum serine repeat antigen- 5 formulated with aluminum hydroxyl gel (BK-SE36) is a blood-stage malaria vaccine candidate. The processing of SERA 5 is believed to mediate parasite egress from the infected red blood cell. Field studies show good correlations of antiSERA antibodies to malaria protection against blood parasitemia, malaria symptoms and severe disease. A Phase 1a trial demonstrated its safety and immunogenicity in malaria naïve Japanese adults. A Phase $1 \mathrm{~b}$ trial was conducted in the malaria endemic area of Northern Uganda to assess the vaccine's safety and immunogenicity. BKSE36 had an acceptable safety and immunogenicity profile. Post-trial, Stage 2 subjects were age-matched to 50 control individuals to compare malaria episodes $130-365$ days post-second vaccination. Log-rank test reveal significant differences in BK-SE36 vaccinees vs control group in time-to-first episodes with parasitemias $\geq 5,000 / \mu \mathrm{L}$ and those with $\geq 5,000 / \mu \mathrm{L}+$ fever (protective efficacy for the latter is $72 \%, P<0.01)$. BK-SE36 vaccinees have fewer multiple malaria episodes with high parasitemia. We also observed that the antibody titers against SE36 were

${ }^{1}$ Research Institute for Microbial Diseases, Osaka University, Suita, Osaka, Japan

Full list of author information is available at the end of the article boosted after episodes of natural infection. Above results show that BK-SE36 could provide some protection against natural $P$. falciparum infection until 1 year post-second vaccination.

\section{Authors' details}

${ }^{1}$ Research Institute for Microbial Diseases, Osaka University, Suita, Osaka, Japan. ${ }^{2}$ Med Biotech Laboratories, Kampala, Uganda. ${ }^{3}$ Makerere University School of Public Health, Kampala, Uganda. ${ }^{4}$ The Research Foundation for Microbial Diseases of Osaka University, Kanonji, Kagawa, Japan. ${ }^{5}$ National Institute of Biomedical Innovation, Ibaraki, Osaka, Japan.

Published: 22 September 2014

doi:10.1186/1475-2875-13-S1-P67

Cite this article as: Palacpac et al:: The development of the BK-SE36

malaria vaccine candidate. Malaria Journal 2014 13(Suppl 1):P67.
Submit your next manuscript to BioMed Central and take full advantage of:

- Convenient online submission

- Thorough peer review

- No space constraints or color figure charges

- Immediate publication on acceptance

- Inclusion in PubMed, CAS, Scopus and Google Scholar

- Research which is freely available for redistribution

Submit your manuscript at www.biomedcentral.com/submit
() Biomed Central 